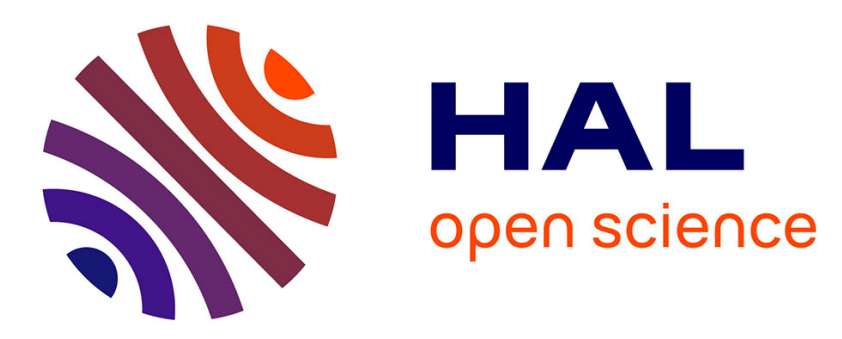

\title{
Scaling size of the interplay between quantum confinement and surface related effects in nanostructured silicon
}

\author{
G. Seguini, Celia Castro, Sylvie Schamm-Chardon, Gérard Benassayag, P. \\ Pellegrino, M. Perego
}

\section{To cite this version:}

G. Seguini, Celia Castro, Sylvie Schamm-Chardon, Gérard Benassayag, P. Pellegrino, et al.. Scaling size of the interplay between quantum confinement and surface related effects in nanostructured silicon. Applied Physics Letters, 2013, 103 (2), pp.023103. 10.1063/1.4813743 hal-01745007

\section{HAL Id: hal-01745007 https://hal.science/hal-01745007}

Submitted on 9 Apr 2018

HAL is a multi-disciplinary open access archive for the deposit and dissemination of scientific research documents, whether they are published or not. The documents may come from teaching and research institutions in France or abroad, or from public or private research centers.
L'archive ouverte pluridisciplinaire HAL, est destinée au dépôt et à la diffusion de documents scientifiques de niveau recherche, publiés ou non, émanant des établissements d'enseignement et de recherche français ou étrangers, des laboratoires publics ou privés. 


\section{Scaling size of the interplay between quantum confinement and surface related effects in nanostructured silicon}

G. Seguini, C. Castro, S. Schamm-Chardon, G. BenAssayag, P. Pellegrino, and M. Perego

Citation: Appl. Phys. Lett. 103, 023103 (2013); doi: 10.1063/1.4813743

View online: https://doi.org/10.1063/1.4813743

View Table of Contents: http://aip.scitation.org/toc/apl/103/2

Published by the American Institute of Physics

\section{Articles you may be interested in}

Quantum confinement in Si and Ge nanostructures: Theory and experiment

Applied Physics Reviews 1, 011302 (2014); 10.1063/1.4835095

Time-resolved photoluminescence spectroscopy of the initial oxidation stage of small silicon nanocrystals

Applied Physics Letters 94, 211903 (2009); 10.1063/1.3141481

The energy band alignment of $\mathrm{Si}$ nanocrystals in $\mathrm{SiO}_{2}$

Applied Physics Letters 99, 082107 (2011); 10.1063/1.3629813

Single-dot spectroscopy of boron and phosphorus codoped silicon quantum dots

Journal of Applied Physics 120, 164307 (2016); 10.1063/1.4965986

Size-controlled highly luminescent silicon nanocrystals: $\mathrm{A} \mathrm{SiO} / \mathrm{SiO}_{2}$ superlattice approach

Applied Physics Letters 80, 661 (2002); 10.1063/1.1433906

Silicon nanocrystals with ensemble quantum yields exceeding $60 \%$

Applied Physics Letters 88, 233116 (2006); 10.1063/1.2210788

\section{Scilight}

Sharp, quick summaries illuminating the latest physics research

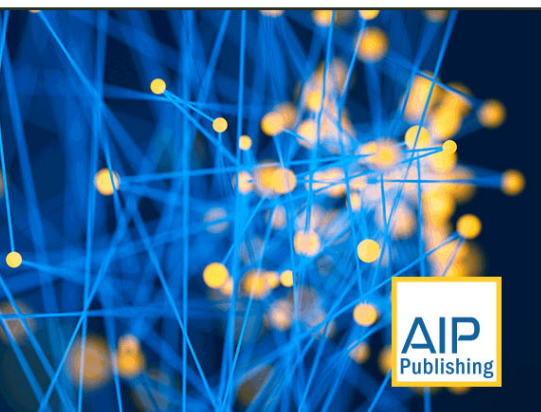




\title{
Scaling size of the interplay between quantum confinement and surface related effects in nanostructured silicon
}

\author{
G. Seguini, ${ }^{1, a)}$ C. Castro, ${ }^{2}$ S. Schamm-Chardon, ${ }^{2}$ G. BenAssayag, ${ }^{2}$ P. Pellegrino, ${ }^{3}$ \\ and M. Perego ${ }^{1}$ \\ ${ }^{1}$ Laboratorio MDM, IMM-CNR, Via C. Olivetti 2, 20864 Agrate Brianza (MB), Italy \\ ${ }^{2}$ CEMES-CNRS and Université de Toulouse, nMat group, BP94345, 31055 Toulouse, Cedex 4, France \\ ${ }^{3}$ MIND, IN2UB, Universitat de Barcelona, cl Martì i Franquès 1, E-08028 Barcelona, Catalunya, Spain
}

(Received 5 June 2013; accepted 24 June 2013; published online 9 July 2013)

\begin{abstract}
$\mathrm{Si}$ nanocrystals (NCs) embedded in a $\mathrm{SiO}_{2}$ matrix provide an exemplar curved nanostructured interface to evidence the competition between surface states and quantum confinement (QC) effects. The study of the energy band alignment as a function of NCs size $(<5 \mathrm{~nm})$ clarifies their interplay and identifies, with subnanometric resolution, three different regimes. Primarily QC affects the conduction band, then surface effects pin the conduction states, and finally QC starts to modify the valence band. A way to study how different nanoscale configurations compete with pure quantum properties is established. (C) 2013 AIP Publishing LLC. [http://dx.doi.org/10.1063/1.4813743]
\end{abstract}

The low dimensionality of semiconductor nanocrystals (NCs) emphasizes peculiar physical properties that arise from the scaling of the matter at nanoscale size. When embedded in an oxide matrix, the resulting non-planar NCs/oxide interface provides an exemplar system to evidence the competition between quantum confinement (QC) and surface states effects in semiconductor based nanostructures. ${ }^{1}$ Beyond this fundamental interest, their remarkable optical and electronic features make the nanostructured semiconductors a promising basic structure to meet the requests of a broad spectrum of functionalities in various application fields such as photovoltaic, ${ }^{2,3}$ optoelectronics, ${ }^{4,5}$ and nanoelectronics. ${ }^{6,7}$

The curved $\mathrm{Si} \mathrm{NCs} / \mathrm{SiO}_{2}$ interfaces encompass all crystal orientation $^{8,9}$ and represent a paradigmatic system to evidence the specific nanoscale physical properties when the $\mathrm{Si}$ NCs dimensions become smaller than the effective Bohr diameter $(8.6 \mathrm{~nm})$. The planar interface between bulk Si and its stoichiometric oxide, $\mathrm{SiO}_{2}$, settled the foremost building block of the microelectronic era. However, since the maximum of the valence band (VB) and the minimum of the conduction band $(\mathrm{CB})$ are not aligned in the energy-crystal momentum $(E-k)$ diagram, the indirect nature of bulk $\mathrm{Si}$ band gap $\left(E_{I N D}=1.12 \mathrm{eV}\right)$ prevented the integration of electronics and photonics functionalities. ${ }^{10} \mathrm{QC}$ effects induce a reduction of the density of delocalized states along with a shift of the energies of the Si NCs VB and CB edges compared with their energy position in bulk $\mathrm{Si}^{11}$ These changes support an energy opening of the $E_{I N D} .{ }^{8}$ Even if the energy structure of the Si NCs is still indirect, the confinement of electrons and holes within the Si NCs volume increases the uncertainty of their crystal momentum causing the relaxation of the $k$-conservation law. These effects result in the detection of size dependent tunable photoluminescence (PL) emission.

Besides the QC effects, the reduced size of the Si NCs causes a remarkable increase of the surface area to volume ratio $(\mathrm{S} / \mathrm{V}){ }^{1,9}$ The $\mathrm{Si} \mathrm{NCs} / \mathrm{SiO}_{2}$ interface is a transition

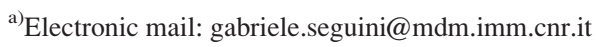

region composed of amorphous $\mathrm{Si}$ and strained $\mathrm{SiO}_{2}$ around Si NCs. ${ }^{12}$ Due to QC and to the corresponding opening of the $E_{I N D}$, surface related defects that in bulk Si have energy states above the $\mathrm{CB}$ or below the VB may appear as localized states within the band gap of nanocrystalline Si. Hence, these states affect the recombination paths. ${ }^{13}$ For sphericallike Si NCs, the diameter where the atoms in the "core" equal the atoms in the "surface" $(\mathrm{S} / \mathrm{V} \sim 1 / 2)$ is around $6 \mathrm{~nm} .{ }^{14}$ Below this critical dimension, the surface related states start to significantly influence the QC phenomena. The crossover from delocalized to localized states is driven by the electron-phonon coupling. ${ }^{15}$ For diameters below $4 \mathrm{~nm}$, the properties of the surrounding interface material dominate the Si NCs electronic structure. ${ }^{16}$

The band alignment at the $\mathrm{Si} \mathrm{NCs} / \mathrm{SiO}_{2}$ interface directly results from the competition of the surface effects on the pure QC ones. Consequently, the study of the energy band alignment as a function of the size of the Si NCs constitutes a straightforward way to investigate, with subnanometric resolution, the size dependence interplay between the pure QC properties and the surface induced effects in nanostructured interfaces. Despite the wide research activity on these nanostructures, only few experimental works are reported on this issue. These reports investigated oxidized porous $\mathrm{Si}$ (Ref. 17) and single $\mathrm{Si}$ NCs coated with $\mathrm{SiO}_{2}{ }^{15}$ The latter configuration allowed a systematic investigation of the electron-phonon coupling evidencing the role of the interfacial $\mathrm{Si}-\mathrm{O}-\mathrm{Si}$ phonons. ${ }^{15,18}$ Recently, a method to directly measure the energy band alignment of Si NCs embedded in $\mathrm{SiO}_{2}$ matrix was established. ${ }^{19}$ However, the complete picture of energy band structure of this system as a function of the size of Si NCs and of the passivation properties of the $\mathrm{Si} \mathrm{NCs} / \mathrm{SiO}_{2}$ interfaces is still lacking. In addition to the basic concern, the $\mathrm{CB}$ and VB discontinuities between Si NCs and $\mathrm{SiO}_{2}$ characterizing the barriers for charge carriers' transport are crucial for the exploitation of the nanostructured interfaces.

In this letter, we present the experimental determination of the energy band alignment of $\mathrm{Si} \mathrm{NCs}$ in a $\mathrm{SiO}_{2}$ matrix 
through independent measurements of their VB and CB edge energy positions with respect to the $\mathrm{SiO}_{2}$ matrix by means of photo-ionization (PI) and capacitance spectroscopy (C-S), respectively. Both techniques capacitively detect the localized charges in Si NCs by monitoring the shift of the flat band voltage $\left(V_{F B}\right)$ in capacitance-voltage $(\mathrm{CV})$ curves, once a variation in the electrical charging is achieved by applying monochromatic light or a short bias stress, respectively. Thus, the obtained VB and CB positions along with the band gap energies measured by PL allow a comprehensive and self-consistent determination of the overall $\mathrm{Si}$ NCs band alignment in the $\mathrm{SiO}_{2}$ host.

A single plane of $\mathrm{Si}$ NCs embedded in a $\mathrm{SiO}_{2}$ matrix was created starting from electron beam deposition of a $\mathrm{SiO}_{2} / \mathrm{SiO} / \mathrm{SiO}_{2}$ multilayer structure in high vacuum regime. Then, to promote the formation of the Si NCs, all the samples were annealed in a conventional quartz-tube furnace at $1050{ }^{\circ} \mathrm{C}$ for $30 \mathrm{~min}$ in $\mathrm{N}_{2}$ flux. ${ }^{20}$ Finally, the samples were annealed in $\mathrm{N}_{2}+\mathrm{H}_{2}$, for $15 \mathrm{~min}$ at $400{ }^{\circ} \mathrm{C}$. The size of the $\mathrm{Si}$ NCs was tuned by changing the nominal thickness of the $\mathrm{SiO}$ layer $(4,6$, and $10 \mathrm{~nm})$ as verified by energy filtered transmission electron microscopy (EFTEM) ${ }^{21}$ whereas all the samples have a 3-nm-thick $\mathrm{SiO}_{2}$ layer as bottom oxide and a 11-nm-thick $\mathrm{SiO}_{2}$ layer as top oxide. Prior to the deposition, all the n-type $\mathrm{Si}(100)$ substrates were properly cleaned to obtain H-terminated Si surface. Metal oxide semiconductors (MOS) capacitors were fabricated by evaporating $\mathrm{Al}$ (15-nm-thick) circular electrodes $\left(0.08-\mathrm{mm}^{2}\right.$-area) as the top gate.

In order to improve the optical signal detection, super lattice structures with several layers of Si NCs embedded in $\mathrm{SiO}_{2}$ matrix are usually employed. ${ }^{22}$ Conversely, in this work, a single layer of Si NCs has been probed. This configuration has many advantages since a detailed electrical testing of the system and a precise structural characterization of the Si NCs are possible, preserving, at the same time, the capability to get a measurable optical signal. In particular, the combination of EFTEM results obtained from two perpendicular directions, i.e., from cross-section and plan-view configurations, provides the possibility to estimate the equivalent mean diameter of the corresponding spherical NCs. The as deposited 4, 6, and $10 \mathrm{~nm}$ thick $\mathrm{SiO}$ films result in $\mathrm{Si}$ NCs layers with equivalent mean diameter of 1.9, 2.8, and $4.3 \mathrm{~nm}$, respectively. The crystalline state of the Si nanoclusters was corroborated by high resolution TEM experiments.

The evaluation of the Si NCs average band gap was performed by PL measurements. The spectra were acquired using a He-Cd laser for excitation $(\lambda=325 \mathrm{~nm}$, power $=50 \mathrm{~mW})$ and a charge coupled device camera covering the $400-900 \mathrm{~nm}$ range for detection. The PL emission spectra before and after thermal treatment in $\mathrm{H}_{2}$-rich ambient are reported in Figures 1(a) and 1(b), respectively. Small but detectable "red" shifts of the PL spectra were observed after the $\mathrm{N}_{2}+\mathrm{H}_{2}$ annealing. This result is ascribed to the $\mathrm{H}$ passivation of paramagnetic defects at the $\mathrm{Si} \mathrm{NCs} / \mathrm{SiO}_{2}$ interface. ${ }^{16,22}$ In both cases, PL measurements indicated a progressive increase of the Si NCs band gap with the reduction of the Si NCs size. After annealing in $\mathrm{H}_{2}$-rich ambient, a strong PL emission peak positioned at $1.40 \pm 0.05 \mathrm{eV}$ was found for the $4.3 \mathrm{~nm}$ diameter Si NCs. The PL peaks shift to $1.50 \mathrm{eV}$ for the $2.8 \mathrm{~nm}$ diameter $\mathrm{Si}$
NCs and to $1.60 \mathrm{eV}$ for the $1.9 \mathrm{~nm}$ diameter Si NCs. The accurate determination of the band gap requires considering that the emission energy is affected by a Stokes shift of $0.25 \mathrm{eV}$ with respect to the absorption energy, irrespective of the size of the Si NCs. ${ }^{23}$ This effect is attributed to the Si-O$\mathrm{Si}, \mathrm{Si}=\mathrm{O}$, or distorted $\mathrm{Si}-\mathrm{Si}$ bonds which are not removed during the thermal treatment in $\mathrm{H}_{2}$-rich-ambient. ${ }^{13,16,22}$ The $\mathrm{Si}-\mathrm{O}-\mathrm{Si}$ can be considered the representative type of bonds. ${ }^{9,15}$ Taking into account this effect, the optical band gaps $\left(E_{G}\right)$ of the $\mathrm{Si}$ NCs embedded in $\mathrm{SiO}_{2}$ matrix were evaluated to be $1.65,1.75$, and $1.85 \mathrm{eV}$, respectively. These values as well as the evolution of the intensity of the PL signal with the Si NCs dimension are in good agreement with data reported in the literature for similar structures with tens of $\mathrm{Si}$ NCs layers embedded in $\mathrm{SiO}_{2}{ }^{22}$

From an underlying point of view, the observed opening of the band gap originates from the energy shifts of the VB $(\triangle \mathrm{VB})$ and $\mathrm{CB}(\Delta \mathrm{CB})$ states. PI and C-S investigations were implemented to determine these shifts. The CV curves for these analyses were acquired sweeping the applied voltage from the inversion to the accumulation regime at $100 \mathrm{KHz}$ in a dark environment. During PI measurements in quantum yield mode, the small changes in the charge population are investigated to identify the energy threshold related to the transition of the Si NCs from the neutral to the positive state. This transition is caused by an optical excitation of the electrons from the $\mathrm{Si} \mathrm{NCs} \mathrm{VB}$ to the $\mathrm{SiO}_{2} \mathrm{CB} .{ }^{24}$ The samples were illuminated with monochromatic light for $5 \mathrm{~min}$ under a positive applied voltage $(\mathrm{V}=+0.5 \mathrm{~V})$ to collect the excited electrons at the metal gate. The low $\mathrm{V}$ prevents charge injections from the $\mathrm{Si}$ substrate. Subsequently a CV curve was acquired. This procedure was repeated at different photon energy values ranging from 2.0 to $6.0 \mathrm{eV}$ with an energy step of $0.1 \mathrm{eV}$. Normalizing the charge variation to the number of incident photons as a function of photon energy, the relative quantum yield $(Y)$ is obtained. The extrapolation of $Y^{1 / 2}$ to zero allows the determination of the barrier energies during the ionization processes. More details about the set up and the technique are available in Refs. 19 and 24. Figure 2 reports the measured spectra. The extrapolated thresholds are 4.30, 4.45, and $4.65 \mathrm{eV}$ for Si NCs with

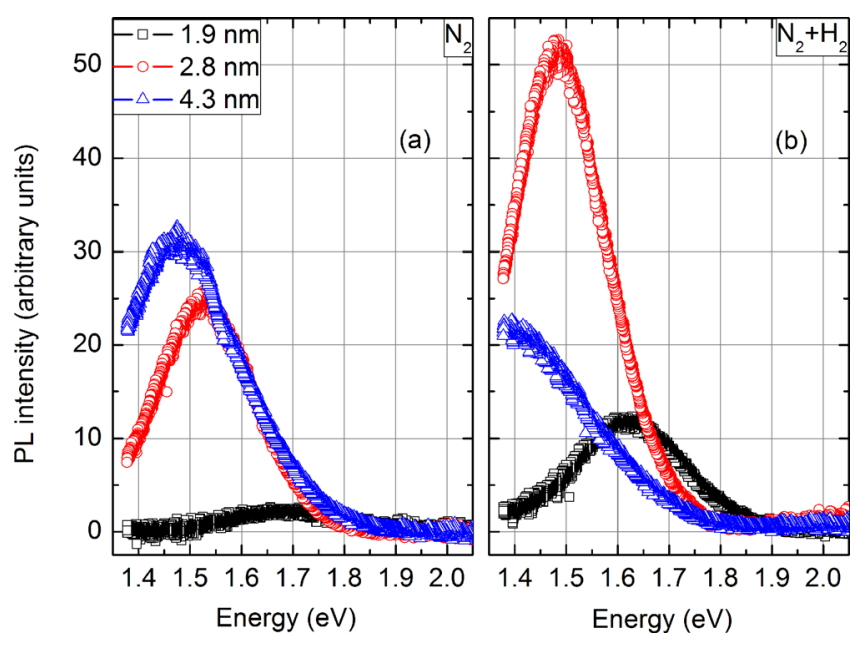

FIG. 1. PL spectra of the 1.9, 2.8, and $4.3 \mathrm{~nm}$ diameter $\mathrm{Si}$ NCs embedded in $\mathrm{SiO}_{2}$ annealed in $\mathrm{N}_{2}$ (a) and in $\mathrm{N}_{2}+\mathrm{H}_{2}$ (b). 


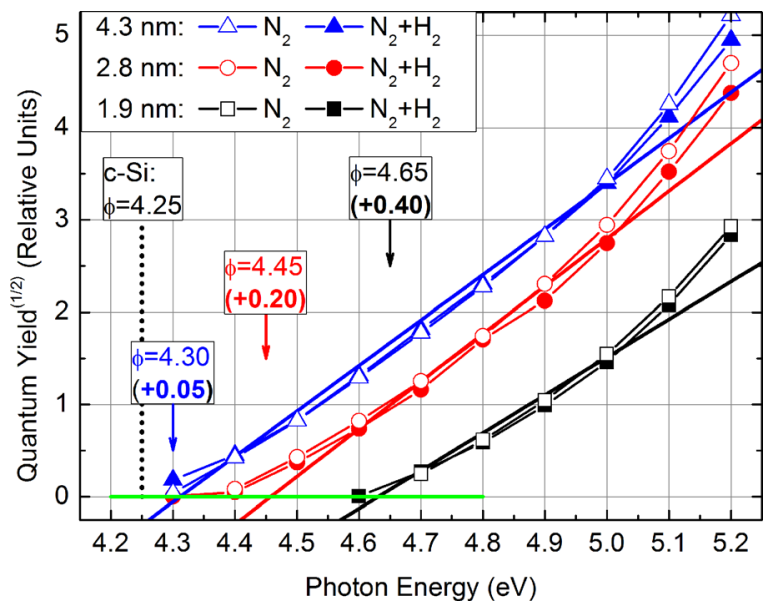

FIG. 2. $Y^{(1 / 2)}$ as function of the photon energy for Si NCs MOS based device after monochromatic photon energy irradiation for $5 \mathrm{~min}$ under positive $(+0.5 \mathrm{~V})$ applied voltage.

mean diameter $4.3,2.8$, and $1.9 \mathrm{~nm}$, respectively. A systematic variation of the selected region to perform the linear fitting near the threshold allowed to evaluate a VB energy spread less than $0.05 \mathrm{eV}$. These values are unaffected by the different passivation treatments. Consequently, these thresholds correspond to transition related to the core states of the Si NCs that are not altered by the surface states. The energy barriers for the electron transition from the Si NCs VB to the $\mathrm{SiO}_{2} \mathrm{CB}$ are higher than the corresponding energy barrier $(4.25 \mathrm{eV})$ for the transition from the bulk $\mathrm{Si} \mathrm{VB}$ to the $\mathrm{SiO}_{2}$ $\mathrm{CB}^{24}$ The resulting VB position of the $\mathrm{Si} \mathrm{NCs}$ is downshifted in energy compared to bulk $\mathrm{Si}$. For the largest $\mathrm{Si}$ NCs, the measured $\triangle \mathrm{VB}$ is negligible $(0.05 \mathrm{eV})$. Decreasing the mean $\mathrm{Si}$ NCs dimension, the magnitude of the $\Delta \mathrm{VB}$ rises up to a value of $0.40 \mathrm{eV}$ for the smallest Si NCs.

By combining the band gap values measured by PL and the $\Delta \mathrm{VB}$ evaluated by PI, we estimate the $\Delta \mathrm{CB}$. The largest $\triangle \mathrm{CB}(0.50 \mathrm{eV})$ appears for the largest Si NCs. The Si NCs $\mathrm{CB}$ energy position slightly lowers by decreasing the size, reaching a value of $0.35 \mathrm{eV}$ for the smallest Si NCs. Hence the $\mathrm{CB}$ offset (energy barrier between the $\mathrm{Si} \mathrm{NCs} \mathrm{CB}$ and the $\mathrm{SiO}_{2} \mathrm{CB}$ ) of the $\mathrm{Si}$ NCs with respect to the $\mathrm{SiO}_{2}$ matrix are expected to increase by reducing the $\mathrm{Si} \mathrm{NCs}$ size. These estimations are compared with the $\Delta \mathrm{CB}$ values that we directly measured by C-S. In this technique electrons are electrically injected in the Si NCs by means of a positive applied voltage $\left(V_{I N J}\right)$ for $1 \mathrm{~s}$. If the $V_{I N J}$ is large enough, the lowest CB level of the Si NCs coincides with the $\mathrm{CB}$ of the Si substrate and the electrons start to tunnel from the $\mathrm{Si}$ substrate into the $\mathrm{Si}$ NCs through the $\mathrm{SiO}_{2}$ potential barrier. The trapping of negative charges in the Si NCs results in a positive shift of the $V_{F B}$. Following the evolution of $V_{F B}$ as a function of $V_{I N J}$, it is possible to determine the threshold value $\left(V_{T H}\right)$ corresponding to the onset of this transition. The value of $\Delta \mathrm{CB} / \mathrm{e}$ corresponds to the potential drop across the $\mathrm{Si} \mathrm{NCs}$ at $V_{I N J}=V_{T H}$. The detailed description of the electrostatic model used to calculate $\triangle \mathrm{CB}$ is reported elsewhere. ${ }^{19} \mathrm{In}$ Figure 3, the evolution of the $V_{F B}$ as a function of $V_{I N J}$ is reported for the different Si NCs diameters. The annealing in $\mathrm{N}_{2}+\mathrm{H}_{2}$ ambient significantly modifies the $V_{F B}$ evolution. It is worth to note that the two different annealing procedures

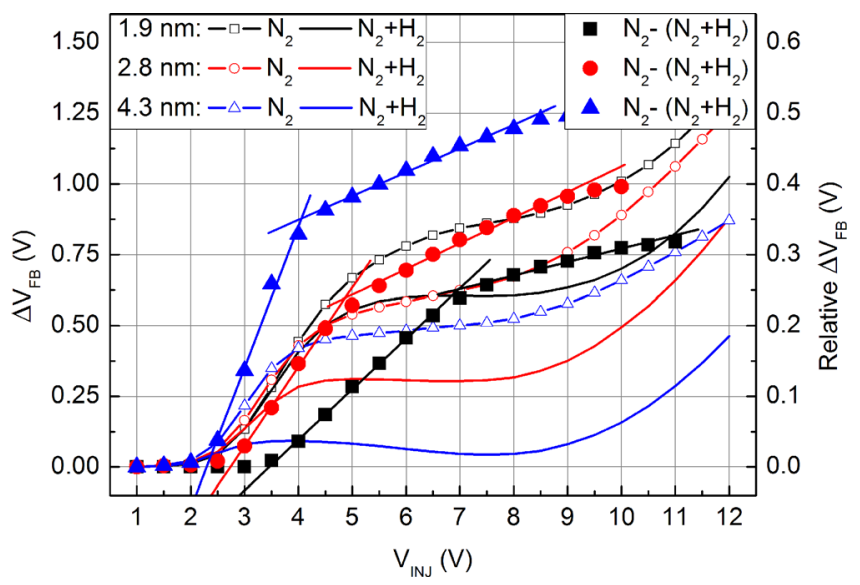

FIG. 3. (Left) $\Delta \mathrm{V}_{\mathrm{FB}}$ as function of the different applied $\mathrm{V}_{\mathrm{INJ}}$ of $\mathrm{Si} \mathrm{NCs}$ based device. (Right) Relative $\Delta \mathrm{V}_{\mathrm{FB}}$ as function of the $\mathrm{V}_{\mathrm{INJ}}$.

cause a noticeable change in the level of passivation. A thermal treatment in $\mathrm{H}_{2}$-rich ambient can drastically decrease the amount of paramagnetic (dangling-bond, $P_{b}$-type) defects at the $\mathrm{Si} \mathrm{NCs} / \mathrm{SiO}_{2}$ interface, while nonparamagnetic defects are unavoidable. ${ }^{22}$ The measurement of the density of interface traps by means of the HillColeman method ${ }^{25}$ indicates a drop of one order of magnitude, from $10^{11}$ to $10^{10} \mathrm{eV}^{-1} \mathrm{~cm}^{-2}$, upon the thermal treatment in $\mathrm{N}_{2}+\mathrm{H}_{2}$ ambient. Considering that the C-S technique is based on the trapping of the injected carriers in the $\mathrm{Si} \mathrm{NCs,} \mathrm{it} \mathrm{is} \mathrm{mandatory} \mathrm{to} \mathrm{get} \mathrm{rid} \mathrm{of} \mathrm{the} \mathrm{contribution}$ from other trapping centers. This result was achieved by subtracting the $\mathrm{V}_{\mathrm{FB}}$ shifts measured on the sample annealed in $\mathrm{N}_{2}$ from those acquired on the samples that experienced the additional treatment in $\mathrm{N}_{2}+\mathrm{H}_{2}$. The result of this procedure is reported in Figure 3. The curves evidence two well distinct series of $V_{T H}$. The first threshold $\left(V_{T H}{ }^{L}\right)$ was found to be positioned at 3.45, 2.75, and $2.30 \mathrm{~V}$ increasing the dimension of the Si NCs. Equally the second threshold $\left(V_{T H}{ }^{H}\right)$ decreases with increasing the Si NCs dimension. The values of $V_{T H}{ }^{H}$ were determined to be $7.00,4.90$, and $4.00 \mathrm{~V}$. From the measured $V_{T H}{ }^{L}$ and $V_{T H}{ }^{H}$ values, we extracted the corresponding $\Delta \mathrm{CB}$ which are $0.20,0.25$, and $0.30 \mathrm{eV}$ for $V_{T H}{ }^{L}$ and $0.45,0.50$, and $0.55 \mathrm{eV}$ for $V_{T H}{ }^{H}$, respectively. It is worth to note that the corresponding values differ for $0.25 \mathrm{eV}$. These findings, together with the fact that the VB position is independent on the passivation treatments, support the idea that the $V_{T H}{ }^{L}$ maps the trapping due to the surface related states at the interface, presumably the same states to take in account for the Stokes shift. Differently, the $V_{T H}{ }^{H}$ is related to the $\Delta \mathrm{CB}$ of the Si NCs. This interpretation is supported by the observation that these values are in very good agreement with those predicted taking in account the band gap energies and VB positions. In order to countercheck the previously described results, the PI and CS measurements were performed on a $\mathrm{SiO}_{2}$ reference sample without Si NCs. The absence of a detectable $\mathrm{V}_{\mathrm{FB}}$ shift indicates that the previously measured phenomena are related to the presence of $\mathrm{Si} \mathrm{NCs}$ embedded in the $\mathrm{SiO}_{2}$ matrix.

In Figure 4, the final picture of the band structure evolution as function the Si NCs size is reported. The data indicate that for the largest $\mathrm{Si} \mathrm{NCs}(4.3 \mathrm{~nm})$ in the $\mathrm{SiO}_{2}$ matrix host the band edges shifts are asymmetric compared to the bulk 


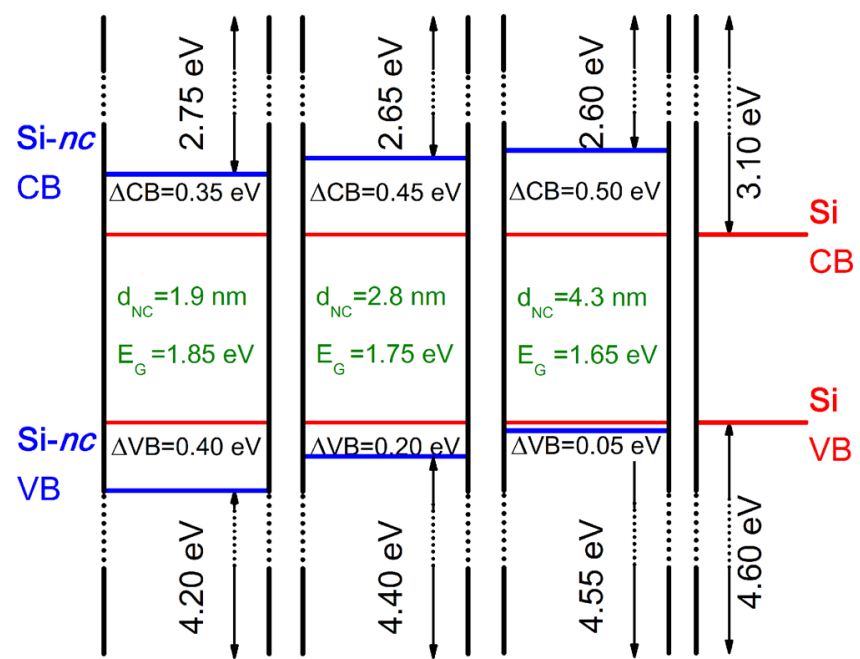

FIG. 4. Band alignments of the 1.9, 2.8, and $4.3 \mathrm{~nm}$ thick Si NCs embedded in $\mathrm{SiO}_{2}$ according to the PL, PI, and C-S measurements.

$\mathrm{Si} / \mathrm{SiO}_{2}$ interface positions. In particular, the $\Delta \mathrm{CB}(0.50 \mathrm{eV})$ is much larger than the $\Delta \mathrm{VB}(0.05 \mathrm{eV})$. Reducing the size of the Si NCs $(2.8 \mathrm{~nm})$, the variation of $\triangle \mathrm{CB}$ is quite limited while $\triangle \mathrm{VB}$ progressively increases. This trend results in a quite symmetrical distribution of the band gap opening for the smallest Si NCs $(1.9 \mathrm{~nm})$ since $\triangle \mathrm{CB}(0.35 \mathrm{eV})$ is substantially equal to $\triangle \mathrm{VB}(0.40 \mathrm{eV})$.

This evolution can be interpreted taking into account different physical phenomena, i.e., QC and surface related effects. For the largest Si NCs $(4.3 \mathrm{~nm})$, the QC effects still overtake the surface related effects and the band gap opening is mainly distributed on $\triangle \mathrm{CB}$ as previously reported. ${ }^{15}$ Decreasing the $\mathrm{Si} \mathrm{NCs}$ dimension $(2.8 \mathrm{~nm})$, the surface related effects pin $\triangle \mathrm{CB}$ while $\triangle \mathrm{VB}$ increases due to $\mathrm{QC}$ effects. ${ }^{17}$ In the smallest Si NCs $(1.9 \mathrm{~nm})$, these phenomena are even more pronounced resulting in the observed symmetrical distribution of the band gap opening. These findings indicated that, in this range of diameters, no pinning of the $\mathrm{VB}$ is induced by the surface related effects, in agreement with previously reported data and theoretical predictions. Indeed, the onset for the pinning of the VB states due to surface related defects is expected to occur well below $2 \mathrm{~nm}$ as already observed for nanoporous $\mathrm{Si}^{17}$ In this size range, the strain inside the Si NCs should be considered as well. ${ }^{9}$ It is worth to note that the previously described evolution of $\triangle \mathrm{CB}$ and $\triangle \mathrm{VB}$ as a function of the NCs size has already been predicted by theoretical calculations for $\mathrm{Si}$ NCs embedded in $\mathrm{SiO}_{2}$. Unfortunately due to the high computational costs of the $a b$ initio simulations, the data available in the literature are mainly limited to Si NCs with diameter below 2 nm. ${ }^{8,26}$ Larger Si NCs require semi empirical approaches. $1,9,26,27$ Moreover, from the experimental point of view, the shrinking of the Si NC dimensions found a bottom limit at $1.6 \mathrm{~nm}$, which corresponds to the minimal size for the crystallization of nanoclusters. $^{22}$ In this regard, the Si NCs diameter we investigate in this work approach the physical limit and thus overlap the ab initio computational accessible dimensions.

In conclusion, a comprehensive and self-consistent measurement of $\mathrm{Si} \mathrm{NCs} / \mathrm{SiO}_{2}$ band alignment in the $\mathrm{Si} \mathrm{NCs}$ mean diameter window between 1.9 and $4.3 \mathrm{~nm}$ has been presented. These findings provide a clear understanding of the electronic structure of the $\mathrm{Si} \mathrm{NCs} / \mathrm{SiO}_{2}$ interface. Indeed, the reported values of the energy band alignment as function of the Si NCs mean diameter set an experimental reference to test the prediction of the numerical simulations. They pave the way to a fine and controllable tuning of the Si NCs band alignment that is extremely important for the implementation of $\mathrm{Si}$ based nanostructures in several functionalities. ${ }^{2-7}$ Considering the dimensions of the nanostructures, the measured data allow the precise determination of the interplay between QC and surface related effects and represent an important starting point for the investigation of this interplay in the general case of semiconductor nanostructures. Finally, the reported exemplar study delineates the capability to use the band alignment evolution as a robust approach to experimental investigate how the different configurations (such as the semiconductor material, ${ }^{28}$ shape, ${ }^{29,30}$ strain, ${ }^{26,31}$ or doping, ${ }^{32,33}$ the host matrix material ${ }^{34,35}$ or density; ${ }^{26}$ and the system dimensionality ${ }^{36}$ ) affect the properties of the nanostructured interfaces.

This research activity has been funded by the "NanoSciE+" consortium through the NANO-BLOCK project. M. Alia and F. Volpe (MDM, IMM-CNR) are acknowledged for support in samples preparation and data analysis, respectively. F. Ferrarese Lupi, D. Sangalli, and A. Lamperti (MDM, IMM-CNR) are acknowledged for fruitful discussions.

${ }^{1}$ A. Puzder, A. J. Williamson, J. C. Grossman, and G. Galli, Phys. Rev. Lett. 88, 097401 (2002).

${ }^{2}$ P. Loper, D. Stuwe, M. Kunle, M. Bivour, C. Reichel, R. Neubauer, M. Schnabel, M. Hermle, O. Eibl, S. Janz, M. Zacharias, and S. W. Glunz, Adv. Mater. 24, 3124 (2012).

${ }^{3}$ M. T. Trinh, R. Limpens, W. D. A. M. de Boer, J. M. Schins, L. D. A. Siebbeles, and T. Gregorkiewicz, Nat. Photonics 6, 316 (2012).

${ }^{4}$ D. Liang and J. E. Bowers, Nat. Photonics 4, 511 (2010).

${ }^{5}$ R. J. Walters, G. I. Bourianoff, and H. A. Atwater, Nature Mater. 4, 143 (2005).

${ }^{6}$ S. Tiwari, F. Rana, H. Hanafi, A. Hartstein, E. F. Crabbè, and K. Chan, Appl. Phys. Lett. 68, 1377 (1996).

${ }^{7}$ L. Guo, E. Leobandung, and S. Chou, Science 275, 649 (1997).

${ }^{8}$ K. Seino, F. Bechstedt, and P. Kroll, Phys. Rev. B 82, 085320 (2010).

${ }^{9}$ G. Hadjisavvas and P. C. Kelires, Phys. Rev. Lett. 93, 226104 (2004).

${ }^{10}$ D. Kovalev, H. Heckler, M. Ben-Chorin, G. Polisski, M. Schwartzkopff, and F. Koch, Phys. Rev. Lett. 81, 2803 (1998).

${ }^{11}$ T. van Buuren, L. N. Dinh, L. L. Chase, W. J. Siekhaus, and L. J. Terminello, Phys. Rev. Lett. 80, 3803 (1998).

${ }^{12}$ N. Daldosso, M. Luppi, S. Ossicini, E. Degoli, R. Magri, G. Dalba, P. Fornasini, R. Grisenti, F. Rocca, L. Pavesi, S. Boninelli, F. Priolo, C. Spinella, and F. Iacona, Phys. Rev. B 68, 085327 (2003).

${ }^{13}$ S. Godefroo, M. Hayne, M. Jivanescu, A. Stesmans, M. Zacharias, O. I. Lebedev, G. van Tendeloo, and V. V. Moshchalkov, Nat. Nanotechnol. 3, 174 (2008).

${ }^{14}$ M. I. Alonso, I. C. Marcus, M. Garriga, A. R. Goni, J. Jedzrejewski, and I. Balberg, Phys. Rev. B 82, 045302 (2010).

${ }^{15}$ J. Martin, F. Cichos, F. Huisken, and C. von Borczyskowski, Nano Lett. 8, 656 (2008).

${ }^{16}$ D. Hiller, S. Goetze, F. Munnik, M. Jivanescu, J. W. Gerlach, J. Vogt, E. Pippel, N. Zakharov, A. Stesmans, and M. Zacharias, Phys. Rev. B 82, 195401 (2010).

${ }^{17}$ M. V. Wolkin, J. Jorne, P. M. Fauchet, G. Allan, and C. Delerue, Phys. Rev. Lett. 82, 197 (1999).

${ }^{18}$ T. Schmidt, A. I. Chizhik, A. M. Chizhik, K. Potrick, A. J. Meixner, and F. Huisken, Phys. Rev. B 86, 125302 (2012).

${ }^{19}$ G. Seguini, S. Schamm-Cardon, P. Pellegrino, and M. Perego, Appl. Phys. Lett. 99, 082107 (2011).

${ }^{20}$ J. Heitmann, F. Müller, M. Zacharias, and U. Gösele, Adv. Mater. 17, 795 (2005). 
${ }^{21}$ S. Schamm, C. Bonafos, H. Coffin, N. Cherkashin, M. Carrada, G. Ben Assayag, A. Claverie, M. Tencé, and C. Colliex, Ultramicroscopy 108, 346 (2008).

${ }^{22}$ B. G. Lee, D. Hiller, J.-W. Luo, O. E. Semonin, M. C. Beard, M. Zacharias, and P. Stradins, Adv. Funct. Mater. 22, 3223 (2012).

${ }^{23}$ B. Garrido, M. Lopez, O. Gonzalez, A. Perez-Rodriguez, J. R. Morante, and C. Bonafos, Appl. Phys. Lett. 77, 3143 (2000).

${ }^{24}$ V. V. Afanas'ev and A. Stesmans, Phys. Rev. B 59, 2025 (1999).

${ }^{25}$ E. H. Nicollian and J. R. Brews, Metal Oxide Semiconductor Physics and Technology (Wiley, New York, 1982).

${ }^{26}$ T. Li, F. Gygi, and G. Galli, Phys. Rev. Lett. 107, 206805 (2011).

${ }^{27}$ C. Bulutay, Phys. Rev. B 76, 205321 (2007).

${ }^{28}$ H.-Ch. Weissker, N. Ning, F. Bechstedt, and H. Vach, Phys. Rev. B 83, 125413 (2011).

${ }^{29}$ A. Gali, E. Kaxiras, G. T. Zimanyi, and S. Meng, Phys. Rev. B 84, 035325 (2011).
${ }^{30}$ W.-Q. Huang, Z.-M. Huang, H.-Q. Cheng, X.-J. Miao, Q. Shu, S.-R. Liu, and C.-J. Qin, Appl. Phys. Lett. 101, 171601 (2012).

${ }^{31}$ K. Kusová, L. Ondič, E. Klimešová, K. Herynková, I. Pelant, S. Daniš, J. Valenta, M. Gallart, M. Ziegler, B. Hönerlage, and P. Gilliot, Appl. Phys. Lett. 101, 143101 (2012).

${ }^{32}$ I. Sychugov, J. Valenta, K. Mitsuishi, and J. Linnros, Phys. Rev. B 86, 075311 (2012).

${ }^{33}$ K. H. Hong, J. Kim, J. H. Lee, J. Shin, and U.-I. Chung, Nano Lett. 10, 1671 (2010).

${ }^{34}$ M. Perego, G. Seguini, C. Wiemer, M. Fanciulli, P.-E. Coulon, and C. Bonafos, Nanotechnology 21, 055606 (2010).

${ }^{35} \mathrm{~N}$. El-Kork, F. Huisken, and C. von Borczyskowsky, J. Appl. Phys. 110, 074312 (2011).

${ }^{36}$ X. Zhao, C. M. Wei, L. Yang, and M. Y. Chou, Phys. Rev. Lett. 92, 236805 (2004). 